\title{
Stable and metastable Si negative-U centers in AlGaN and AIN
}

\author{
Xuan Thang Trinh, Daniel Nilsson, Ivan Gueorguiev Ivanov, Erik Janzén, Anelia \\ Kakanakova-Georgieva and Nguyen Tien Son
}

\section{Linköping University Post Print}

\section{Tweet}

N.B.: When citing this work, cite the original article.

Original Publication:

Xuan Thang Trinh, Daniel Nilsson, Ivan Gueorguiev Ivanov, Erik Janzén, Anelia KakanakovaGeorgieva and Nguyen Tien Son, Stable and metastable Si negative-U centers in AlGaN and AlN, 2014, Applied Physics Letters, (105), 16, 162106-1-162106-4.

http://dx.doi.org/10.1063/1.4900409

Copyright: American Institute of Physics (AIP) http://www.aip.org/

Postprint available at: Linköping University Electronic Press http://urn.kb.se/resolve?urn=urn:nbn:se:liu:diva-112407 


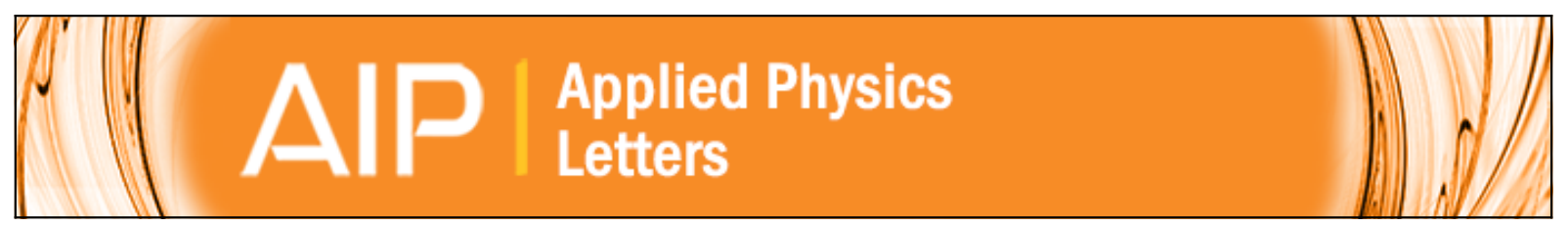

\section{Stable and metastable Si negative-U centers in AIGaN and AIN}

Xuan Thang Trinh, Daniel Nilsson, Ivan G. Ivanov, Erik Janzén, Anelia Kakanakova-Georgieva, and Nguyen Tien Son

Citation: Applied Physics Letters 105, 162106 (2014); doi: 10.1063/1.4900409

View online: http://dx.doi.org/10.1063/1.4900409

View Table of Contents: http://scitation.aip.org/content/aip/journal/apl/105/16?ver=pdfcov

Published by the AIP Publishing

\section{Articles you may be interested in}

Negative-U behavior of the Si donor in Al0.77Ga0.23N

Appl. Phys. Lett. 103, 042101 (2013); 10.1063/1.4816266

The complex impact of silicon and oxygen on the n-type conductivity of high-Al-content AIGaN Appl. Phys. Lett. 102, 132113 (2013); 10.1063/1.4800978

Deep centers and persistent photocapacitance in AIGaN/GaN high electron mobility transistor structures grown on Si substrates

J. Vac. Sci. Technol. B 31, 011211 (2013); 10.1116/1.4773057

Spatial distribution of deep level defects in crack-free AIGaN grown on GaN with a high-temperature AIN interlayer

J. Appl. Phys. 100, 123101 (2006); 10.1063/1.2402964

Photoluminescence studies of impurity transitions in AIGaN alloys

Appl. Phys. Lett. 89, 092107 (2006); 10.1063/1.2337856

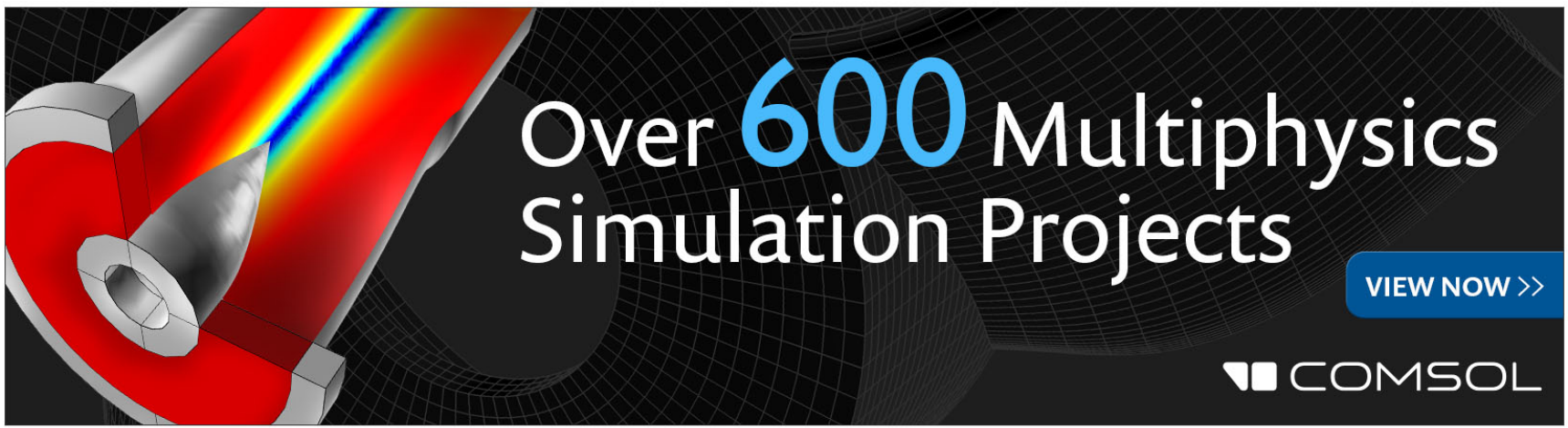




\title{
Stable and metastable Si negative-U centers in AIGaN and AIN
}

\author{
Xuan Thang Trinh, Daniel Nilsson, Ivan G. Ivanov, Erik Janzén, \\ Anelia Kakanakova-Georgieva, and Nguyen Tien Son \\ Department of Physics, Chemistry and Biology, Linköping University, SE-58183 Linköping, Sweden
}

(Received 5 August 2014; accepted 8 October 2014; published online 23 October 2014)

\begin{abstract}
Electron paramagnetic resonance studies of $\mathrm{Si}$-doped $\mathrm{Al}_{\mathrm{x}} \mathrm{Ga}_{1-\mathrm{x}} \mathrm{N}(0.79 \leq \mathrm{x} \leq 1.0)$ reveal two $\mathrm{Si}$ negative-U (or DX) centers, which can be separately observed for $\mathrm{x} \geq 0.84$. We found that for the stable DX center, the energy $\left|\mathrm{E}_{\mathrm{DX}}\right|$ of the negatively charged state $\mathrm{DX}^{-}$, which is also considered as the donor activation energy, abruptly increases with $\mathrm{Al}$ content for $\mathrm{x} \sim 0.83-1.0$ approaching $\sim 240 \mathrm{meV}$ in AlN, whereas $\mathrm{E}_{\mathrm{DX}}$ remains to be close to the neutral charge state $\mathrm{E}_{\mathrm{d}}$ for the metastable DX center ( $\sim 11 \mathrm{meV}$ below $\mathrm{E}_{\mathrm{d}}$ in AlN). (C 2014 AIP Publishing LLC.

[http://dx.doi.org/10.1063/1.4900409]
\end{abstract}

High-efficiency compact deep-ultraviolet (UV) light sources such as light-emitting diodes and laser diodes for replacing low-efficiency and toxic gas lasers and mercury lamps used in water/air purification and disinfection or highresolution photolithography have so far been developed based on $\mathrm{AlN}^{1}$ and high-Al-content $\mathrm{AlGaN}^{2,3}$ In such devices, high $n$-type conductivity is required. Silicon $(\mathrm{Si})$ is used for the $n$-type doping but achieving highly conductive $n$-type $\mathrm{Al}_{\mathrm{x}} \mathrm{Ga}_{1-\mathrm{x}} \mathrm{N}$ for $\mathrm{x} \geq 0.70$ is proven difficult. A sharp increase in the donor activation energy $\mathrm{E}_{\mathrm{a}}^{4-6}$ and resistivity ${ }^{7}$ was reported for Si-doped $\mathrm{Al}_{\mathrm{x}} \mathrm{Ga}_{1-\mathrm{x}} \mathrm{N}$ with $\mathrm{x}$ in the range of $\sim 0.8-1.0$. Carrier compensation by deep level defects, including deep Si DX (or negative-U) centers, has often been speculated.

Different calculations ${ }^{8,9}$ suggested Si to be a deep DX center in AlN. In the neutral charge state $\mathrm{d}^{0}$, a Si donor prefers to capture another electron and undergoes a large lattice relaxation, relaxing to its lower-lying negatively charged state $\mathrm{DX}^{-}$according to the process: $2 \mathrm{~d}^{0} \rightarrow \mathrm{DX}^{-}+\mathrm{d}^{+}$(here $\mathrm{d}^{+}$is the positive charge state of the donor). Depending on the energy separation between the $\mathrm{d}^{0}$ and $\mathrm{DX}^{-}$state, $\mathrm{E}_{\mathrm{d}^{-}}$ $E_{D X}$, is small or large compared to $E_{d}$; such a DX donor may behave as a shallow donor or a self-compensation center. Some hybrid functional calculations in $\mathrm{AlN}^{10,11}$ have found two configurations of Si DX donors: a stable $\mathrm{DX}_{1}$ center with the broken Si-N bond along the $c$ axis and a metastable $\mathrm{DX}_{2}$ center related to one of three equivalent broken Si-N basal bonds. A more recent calculation predicted no DX-like behavior for Si in AlN and suggested that the $n$-type conductivity in AlN is caused by the cluster of four Si and an $\mathrm{Al}$ vacancy, $\mathrm{V}_{\mathrm{Al}}-4 \mathrm{Si}$, which is predicted to have a formation energy lower than that of the substitutional $\mathrm{Si}_{\mathrm{Al}}$ donor. ${ }^{12}$

In a Raman spectroscopy study of GaN:Si under hydrostatic pressure, where the results can be transferred to $\mathrm{Al}_{\mathrm{X}} \mathrm{Ga}_{1-\mathrm{x}} \mathrm{N}$, no DX behavior was detected for $\mathrm{x}$ up to $\sim 0.56 .{ }^{13}$ A later transport study ${ }^{14}$ suggested $\mathrm{Si}$ to be a DX center in $\mathrm{Al}_{\mathrm{x}} \mathrm{Ga}_{1-\mathrm{x}} \mathrm{N}$ for $\mathrm{x} \geq 0.5$. In electron paramagnetic resonance (EPR) studies of Si-doped $\mathrm{Al}_{\mathrm{x}} \mathrm{Ga}_{1-\mathrm{x}} \mathrm{N}(\mathrm{x} \geq 0.75)^{15}$ and $\mathrm{AlN},{ }^{16}$ the requirement of illumination at low temperatures $(\mathrm{T}<60 \mathrm{~K})$ for detecting the signal of the shallow donor was explained by the DX-like nature of Si. However, a later EPR study suggested that $\mathrm{Si}$ is a shallow donor in AlN and explained the failure of detecting its EPR signal in darkness to be due to carrier compensation by deeper electron traps. ${ }^{17}$ The DX behavior was also reported for donors in undoped AlN ${ }^{18}$ which was later suggested to be related to the oxygen donor $\mathrm{O}_{\mathrm{N}}{ }^{19}$ A recent EPR study of Si-doped $\mathrm{Al}_{0.77} \mathrm{Ga}_{0.23} \mathrm{~N}^{20}$ suggested that $\mathrm{Si}$ forms a stable $\mathrm{DX}^{-}$state already for $\mathrm{x} \sim 0.77$ but its influence on the n-type conductivity is not essential since the neutral state $E_{d}$ lies only $\sim 3 \mathrm{meV}$ above the Fermi level $E_{F}$. In AlN, the energy separation $E_{d}-E_{F}$ increases to $\sim 78 \mathrm{meV} .{ }^{21}$ A recent hybrid functional calculation $^{22}$ suggested that $\mathrm{Si}$ transforms to a DX center in AlGaN when the $\mathrm{Al}$ content reaches $~ 94 \%$.

In this letter, EPR was used to study $\mathrm{Si}$-doped $\mathrm{Al}_{\mathrm{x}} \mathrm{Ga}_{1-\mathrm{x}} \mathrm{N}$ epitaxial layers, $0.79 \leq \mathrm{x} \leq 1.0$, grown by metalorganic chemical vapor deposition (MOCVD). The energy levels of $\mathrm{DX}^{-}$and $\mathrm{d}^{0}$ states were determined from the temperature dependence of the $\mathrm{Si}$ concentration in the neutral state $\mathrm{d}^{0}$. From EPR experiments, we found the existence of two DX configurations of the Si donor for $\mathrm{x} \geq 0.84$ : one with $E_{D X}$ remaining close to $E_{d}$ and the other with $E_{D X}$ increasing linearly and drastically with the $\mathrm{Al}$ content. The drastic deepening of the stable DX center explains the sharp decrease of the conductivity often observed in transport measurements.

Si-doped $\mathrm{Al}_{\mathrm{x}} \mathrm{Ga}_{1-\mathrm{x}} \mathrm{N}(0.79 \leq \mathrm{x} \leq 1)$ layers with typical thickness of $\sim 400-600 \mathrm{~nm}$ were grown by MOCVD on semi-insulating $4 \mathrm{H}-\mathrm{SiC}$ substrates using silane $\left(\mathrm{SiH}_{4}\right)$ as dopant gas. Further details about the growth processes can be found elsewhere. ${ }^{23,24}$ The $\mathrm{Al}$ content, the thickness of the $\mathrm{Al}_{\mathrm{x}} \mathrm{Ga}_{1-\mathrm{x}} \mathrm{N}: \mathrm{Si}$ layers, and the atomic concentration of $\mathrm{Si}, \mathrm{O}$, and $\mathrm{C}$ were determined by secondary ion mass spectrometry (SIMS) by Evans Analytical Group (the notation [] is used in this paper to denote the concentration obtained from SIMS). In all studied samples, the concentration of $\mathrm{Si}$ was kept at $[\mathrm{Si}] \sim 2 \times 10^{18} \mathrm{~cm}^{-3}$ while the concentrations of $\mathrm{O}$ and $\mathrm{C}$ were reduced to the detection limit of SIMS $\left([\mathrm{O}] \sim[\mathrm{C}] \sim 2 \times 10^{17} \mathrm{~cm}^{-3}\right.$ ) so that the influence of these impurities on the free-carrier concentration and EPR results can be neglected. At such a moderate Si doping level, layers usually have good morphology and conductivity, which are important factors to guarantee the observation of good EPR signal of the shallow donor in darkness (It is known from our previous study ${ }^{23}$ that in layers with high Si doping and pit-populated morphology, neither conductivity nor EPR signal can be detected). For the studied samples, XRD 


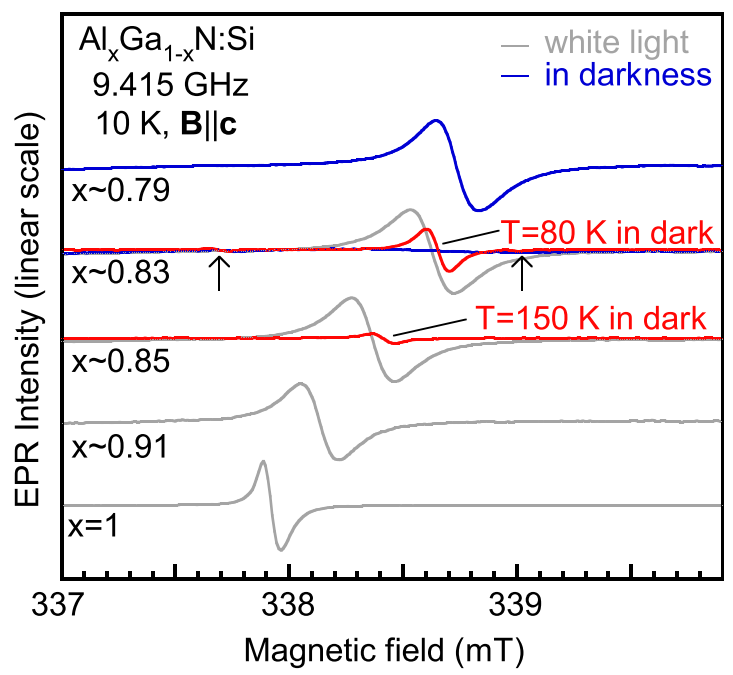

FIG. 1. EPR spectra of $\mathrm{Al}_{\mathrm{x}} \mathrm{Ga}_{1-\mathrm{x}} \mathrm{N}: \mathrm{Si}$ measured at $10 \mathrm{~K}$ for $\mathbf{B} \| \mathbf{c}$. The EPR spectra of $\mathrm{Al}_{0.83} \mathrm{Ga}_{0.17} \mathrm{~N}$ measured at $80 \mathrm{~K}$ and $\mathrm{Al}_{0.85} \mathrm{Ga}_{0.15} \mathrm{~N}$ at $150 \mathrm{~K}$ in darkness were also given for comparison. The EPR signal of the Si shallow donor could be detected in darkness in $\mathrm{Al}_{\mathrm{x}} \mathrm{Ga}_{1_{-\mathrm{x}} \mathrm{N}} \mathrm{N}$ :Si layers with $\mathrm{x}=0.79$, while in layers with $x \geq 0.83$, the observation of the EPR signal required illumination or thermal excitation at elevated temperatures. The arrows indicate the positions of the Si hyperfine lines of the carbon vacancy defect ${ }^{26}$ from the $4 \mathrm{H}-\mathrm{SiC}$ substrate.

rocking curves of the (0002) and (1012) plane reflections were measured with full width at half maximum of about 100-200 arcsec and 380-480 arcsec, respectively. Using the method given by Lee et $\mathrm{al}^{25}$ the screw and edge dislocation densities were estimated to be about $(4 \pm 2) \times 10^{7} \mathrm{~cm}^{-3}$ and $(2 \pm 1) \times 10^{9} \mathrm{~cm}^{-3}$, respectively. EPR measurements were performed on an X-band $(\sim 9.4 \mathrm{GHz})$ E500 Bruker spectrometer equipped with a continuous He-flow cryostat, allowing the regulation of the sample temperature from 4 to $295 \mathrm{~K}$. For illumination, $200 \mathrm{~W}$-halogen or $150 \mathrm{~W}$-xenon lamps was used as a light source. The donor concentration or the number of spins was determined using the spin counting application provided and calibrated by Bruker.

In $\mathrm{Al}_{0.79} \mathrm{Ga}_{0.21} \mathrm{~N}: \mathrm{Si}$ layers, the signal of the shallow donor could be detected in darkness at $10 \mathrm{~K}$ (Fig. 1) similar to the case of $\mathrm{Al}_{0.77} \mathrm{Ga}_{0.23} \mathrm{~N}$ :Si for which the neutral state $\mathrm{d}^{0}$ is $\sim 3 \mathrm{meV}$ above the Femi level, ${ }^{20}$ and the thermal-induced population on $\mathrm{d}^{0}$ at low temperatures is detectable by EPR. In layers with $\mathrm{x} \sim 0.83-0.85$, the EPR signal can still be detected in darkness, but only at elevated temperatures

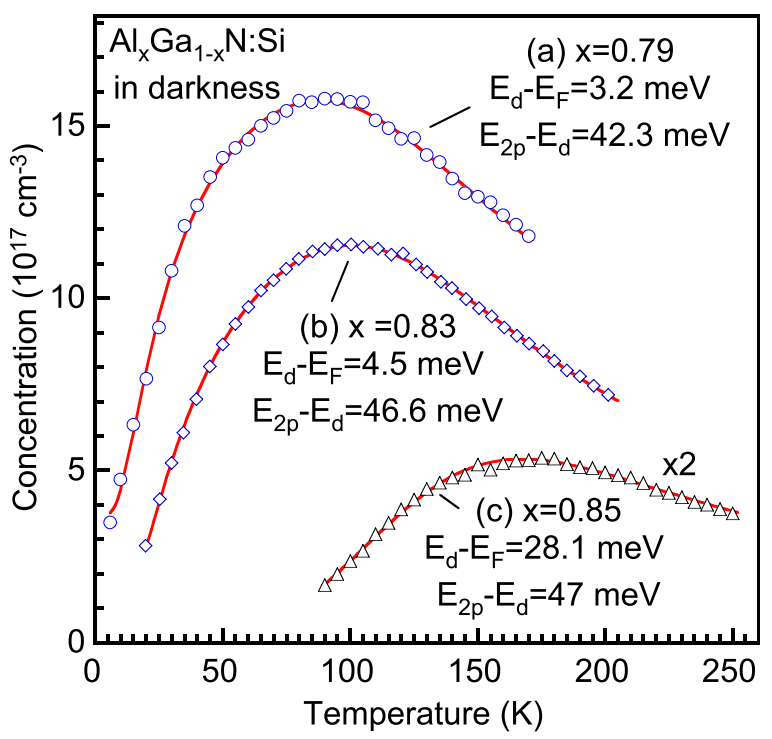

FIG. 2. Temperature dependence of the donor concentration in the $\mathrm{d}^{0}$ state in darkness in $\mathrm{Al}_{\mathrm{x}} \mathrm{Ga}_{1-\mathrm{x}} \mathrm{N}$ :Si layers with (a) $\mathrm{x} \sim 0.79$, (b) $\mathrm{x} \sim 0.83$ and (c) $\mathrm{x} \sim 0.85$. The donor concentration in the $\mathrm{Al}_{0.85} \mathrm{Ga}_{0.15} \mathrm{~N}: \mathrm{Si}$ layer was shown in $\times 2$ scale. The solid curves represent the fits using Eq. (2).

( $\mathrm{T} \geq 30 \mathrm{~K}$ for $\mathrm{x} \sim 0.83$ and $\mathrm{T} \geq 80 \mathrm{~K}$ for $\mathrm{x} \sim 0.85$ ). Since the Si-doped layer in all samples is thin $(\sim 400-600 \mathrm{~nm})$, the total number of $\mathrm{Si}$ in the neutral state induced by thermal energy with the $\mathrm{Al}$ content exceeding $\sim 0.85$ is below the detection limit of EPR. In these layers, the EPR signal of the Si donor could only be detected under or after illumination with light of photon energies in the range $\sim 1.6-2.9 \mathrm{eV}$ depending on the $\mathrm{Al}$ content.

Figure 2 shows the temperature dependence of the concentration of the shallow donor $\mathrm{n}(\mathrm{T})$ in the neutral charge state $\mathrm{d}^{0}$ in $\mathrm{Al}_{\mathrm{x}} \mathrm{Ga}_{1-\mathrm{x}} \mathrm{N}: \mathrm{Si}$ layers of $\mathrm{x} \sim 0.79-0.85$ determined from EPR measurements in darkness. The measurements performed with the microwave power varying in the range from $0.1 \mathrm{~mW}$ to $4 \mathrm{~mW}$ gave the same $\mathrm{n}(\mathrm{T})$ values, indicating that under these measurement conditions, no partial saturation occurred and the EPR signal was proportional to $n(T)$. In all samples, $\mathrm{n}(\mathrm{T})$ is smallest at the lowest temperature and increases to a maximum at a certain temperature. Such temperature dependence is typical for a DX center. The average population on the $\mathrm{d}^{0}$ state in a negative- $\mathrm{U}$ center can be described by the Boltzmann distribution ${ }^{27}$ with including the excited states ${ }^{28,29}$

$$
\mathrm{n}(\mathrm{T}) \propto \frac{\mathrm{N} 2 \mathrm{e}^{-\left(\mathrm{E}_{\mathrm{d}}-\mathrm{E}_{\mathrm{F}}\right) / \mathrm{k}_{\mathrm{B}} \mathrm{T}}}{1+2 \mathrm{e}^{-\left(\mathrm{E}_{\mathrm{d}}-\mathrm{E}_{\mathrm{F}}\right) / \mathrm{k}_{\mathrm{B}} \mathrm{T}}+\mathrm{e}^{-\left\{2 \mathrm{E}_{\mathrm{d}}-\left(\mathrm{E}_{\mathrm{d}}-\mathrm{E}_{\mathrm{DX}}\right)-2 \mathrm{E}_{\mathrm{F}}\right\} / \mathrm{k}_{\mathrm{B}} \mathrm{T}}+\sum_{\mathrm{i}} \mathrm{G}_{\mathrm{i}} \mathrm{e}^{-\left(\mathrm{E}_{\mathrm{i}}-\mathrm{E}_{\mathrm{F}}\right) / \mathrm{k}_{\mathrm{B}} \mathrm{T}}} .
$$

Here, $\mathrm{N}$ is the total donor concentration, $\mathrm{k}_{\mathrm{B}}$ is the Boltzmann constant, $E_{i}$ and $G_{i}$ are the energy level of excited states and their degenerate factors, respectively. It has been shown that in a negative- $\mathrm{U}$ center, the Fermi level is pinned at the middle of $\mathrm{E}_{\mathrm{d}}$ and $\mathrm{E}_{\mathrm{DX}}$ levels (i.e., $\mathrm{E}_{\mathrm{F}}-\mathrm{E}_{\mathrm{DX}}=\mathrm{E}_{\mathrm{d}}-\mathrm{E}_{\mathrm{F}}$ ) almost independently of the electron density on the levels. ${ }^{27,29} \mathrm{~A}$ recent calculation of Si DX center in $\mathrm{AlGaN}$ and $\mathrm{AlN}^{22}$ also showed that the Fermi level is located at the middle between $E_{d}$ and $E_{D X}$ levels. Thus, with considering only the first excited state 2p, Eq. (1) can be rewritten as 


$$
\begin{aligned}
& \mathrm{n}(\mathrm{T}) \propto \frac{\mathrm{N}}{1+0.5 \mathrm{e}^{\left(\mathrm{E}_{\mathrm{d}}-\mathrm{E}_{\mathrm{F}}\right) / \mathrm{k}_{\mathrm{B}} \mathrm{T}}+0.5 \mathrm{e}^{\left(\mathrm{E}_{\mathrm{F}}-\mathrm{E}_{\mathrm{DX}}\right) / \mathrm{k}_{\mathrm{B}} \mathrm{T}}+\mathrm{Ce}^{-\left(\mathrm{E}_{2 \mathrm{p}}-\mathrm{E}_{\mathrm{d}}\right) / \mathrm{k}_{\mathrm{B}} \mathrm{T}}}, \\
& \mathrm{n}(\mathrm{T}) \propto \frac{\mathrm{N}}{1+\mathrm{e}^{\left(\mathrm{E}_{\mathrm{d}}-\mathrm{E}_{\mathrm{F}}\right) / \mathrm{k}_{\mathrm{B}} \mathrm{T}}+\mathrm{Ce}^{-\left(\mathrm{E}_{2 \mathrm{p}}-\mathrm{E}_{\mathrm{d}}\right) / \mathrm{k}_{\mathrm{B}} \mathrm{T}}} .
\end{aligned}
$$

Here, $E_{2 p}-E_{d}$ is the energy distance from $d^{0}\left(E_{d}\right.$ or $\left.E_{1 s}\right)$ to first excited state $2 p$, and $C$ is a factor taking into account the thermal excitation from the first excited state to higher-lying excited states (including their degeneration factors). From the best fits to experimental data using Eq. (2), $E_{d}-E_{F}$ was found to increase drastically from $\sim 3-5 \mathrm{meV}$ for $\mathrm{x}=0.79-0.83$ to $\sim 28 \mathrm{meV}$ for $\mathrm{x} \sim 0.85$. The value $\mathrm{E}_{2 \mathrm{p}}-\mathrm{E}_{\mathrm{d}}$ was determined to be $\sim 42.3 \mathrm{meV}$ for $\mathrm{x} \sim 0.79$ and $\sim 47 \mathrm{meV}$ for $\mathrm{x}=0.85$. Assuming that the neutral state $\mathrm{E}_{\mathrm{d}}$ and excited states of the $\mathrm{Si}$ donor follow the effective mass theory (EMT), i.e., the $E_{d} / i^{2}$ rule $(i=1,2, ., n)$ or $E_{2 p} \sim E_{d} / 4$ and $\left|\mathrm{E}_{2 \mathrm{p}}-\mathrm{E}_{\mathrm{d}}\right|=\left|\left(\mathrm{E}_{\mathrm{d}} / 4\right)-\mathrm{E}_{\mathrm{d}}\right|=3\left|\mathrm{E}_{\mathrm{d}}\right| / 4$, we can estimate $\left|\mathrm{E}_{\mathrm{d}}\right|$ as: $\left|\mathrm{E}_{\mathrm{d}}\right|=4\left|\mathrm{E}_{2 \mathrm{p}}-\mathrm{E}_{\mathrm{d}}\right| / 3 \sim 56.8, \sim 62,63.3$ and $\sim 64.6 \mathrm{meV}$ for $\mathrm{X} \sim 0.79, \sim 0.83,0.84$, and $\sim 0.85$, respectively. In all studied samples, the values of the total concentration of the Si donor obtained from the fits are in the range of $3-4 \times 10^{18} \mathrm{~cm}^{-3}$, which are higher than the $\mathrm{Si}$ concentration obtained from SIMS $\left(\sim 2 \times 10^{18} \mathrm{~cm}^{-3}\right)$. This systematic overestimation of the donor concentration by EPR may be due to the calibration in Bruker program. The degeneration factor $\mathrm{C}$ is about 20-30 for the Al content $\mathrm{x}$ in the range of $0.79-0.83$ and $\mathrm{C} \sim 110$ for $\mathrm{x}=0.85$. In higher $\mathrm{Al}$-content samples, the decrease of $n(T)$ occurs at higher temperatures at which electrons can be more efficiently moved to excited states. Therefore, higher values of the $\mathrm{C}$ factor are expected for higher Al-content samples.

Using the effective mass values and dielectric constants interpolated from GaN and AlN as described in previous studies $^{20}$ to calculate the donor ionization energy in $\mathrm{Al}_{\mathrm{x}} \mathrm{Ga}_{1-\mathrm{x}} \mathrm{N}$, we obtained the EMT values for different $\mathrm{Al}$

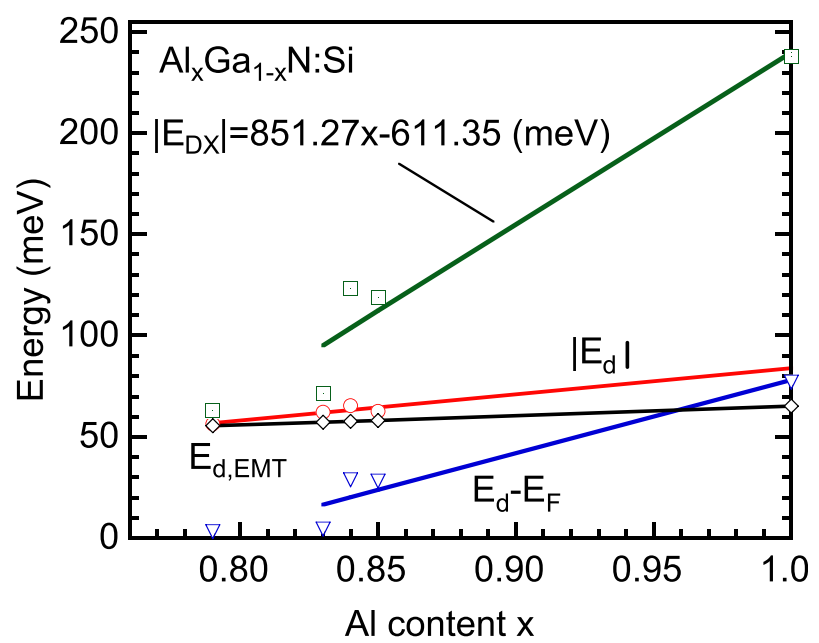

FIG. 3. The linear dependence on the $\mathrm{Al}$ content of the ionization energy of the neutral charge state $d^{0}\left(E_{d}\right)$, the $D X^{-}$state $\left(\left|E_{D X}\right|=E_{a}\right)$, and the energy separation $\mathrm{E}_{\mathrm{d}}-\mathrm{E}_{\mathrm{F}}$ in $\mathrm{Al}_{\mathrm{x}} \mathrm{Ga}_{1-\mathrm{x}} \mathrm{N}$ : Si with $0.79 \leq \mathrm{x} \leq 1$. The dependence of the ionization energy $\mathrm{E}_{\mathrm{d}, \mathrm{EMT}}$ on the $\mathrm{Al}$ content obtained from EMT calculations is also plotted for comparison. The $\left|\mathrm{E}_{\mathrm{DX}}\right|$ value for AlN was measured in an unintentionally Si-doped AlN bulk sample similar to the one previously used in Ref. 21. contents $\mathrm{E}_{\mathrm{d}, \mathrm{EMT}}$. The calculated $\mathrm{E}_{\mathrm{d}, \mathrm{EMT}}$ values and the $\left|\mathrm{E}_{\mathrm{d}}\right|$ values obtained from experiments are shown in Fig. 3. Extrapolation from the linear fit to the obtained $\left|\mathrm{E}_{\mathrm{d}}\right|$ values gives $\left|\mathrm{E}_{\mathrm{d}}\right| \sim 84 \mathrm{meV}$ for AlN with a deviation of $\sim 19 \mathrm{meV}$ from the corresponding EMT value $(65.2 \mathrm{meV})$.

The energy separation $\mathrm{E}_{\mathrm{d}}-\mathrm{E}_{\mathrm{F}}$ was determined to be: $\sim 3.2, \sim 4.5, \sim 28.8$ and $28.1 \mathrm{meV}$ for $\mathrm{Al}_{\mathrm{x}} \mathrm{Ga}_{1-\mathrm{x}} \mathrm{N}$ layers with $\mathrm{x} \sim 0.79, \sim 0.83, \sim 0.84$ and $\sim 0.85$, respectively. In our previous studies, ${ }^{20,21}$ the term related to the $\mathrm{DX}^{-}$state in the partition function, i.e., the third term in the denominator of Eq. (1), was neglected. Using Eq. (2), we analyzed the data in Refs. 20 and 21 and obtained small changes, e.g., $\mathrm{E}_{\mathrm{d}^{-}}$ $\mathrm{E}_{\mathrm{F}} \sim 2.3$ and $\sim 77 \mathrm{meV}$ compared to the values of $\sim 2.8$ and $\sim 78 \mathrm{meV}$ for $\mathrm{Si}$ in $\mathrm{Al}_{0.77} \mathrm{Ga}_{0.23} \mathrm{~N}$ and AlN, respectively. ${ }^{20,21}$ The $\mathrm{E}_{\mathrm{DX}}$ levels of $\mathrm{Si}$ in $\mathrm{Al}_{\mathrm{x}} \mathrm{Ga}_{1-\mathrm{x}} \mathrm{N}$ with $\mathrm{x} \sim 0.79, \sim 0.83$, $\sim 0.84, \sim 0.85$ and in AlN were estimated to be $\left|\mathrm{E}_{\mathrm{DX}}\right| \sim\left|\mathrm{E}_{\mathrm{d}}\right|+2\left|\mathrm{E}_{\mathrm{d}}-\mathrm{E}_{\mathrm{F}}\right| \sim 63, \quad \sim 71, \quad \sim 123, \quad \sim 119$ and $\sim 238 \mathrm{meV}$, respectively. The obtained $\left|\mathrm{E}_{\mathrm{d}}-\mathrm{E}_{\mathrm{F}}\right|$ and $\left|\mathrm{E}_{\mathrm{DX}}\right|$ values are shown in Fig. 3. The best fit to $\left|E_{D X}\right|$ values for $\mathrm{x} \geq 0.83$ gave the dependence of $\left|\mathrm{E}_{\mathrm{DX}}(\mathrm{x})\right|$ on the $\mathrm{Al}$ content as

$$
\left|\mathrm{E}_{\mathrm{DX}}(\mathrm{x})\right|=851.27 \mathrm{x}-611.35(\mathrm{meV}) .
$$

For $\mathrm{x} \geq 0.83$, the observation of strong EPR signals of the $\mathrm{Si}$ donor at low temperatures required illumination. After illumination, the EPR signals of the Si donor were persistent for hours in darkness for $\mathrm{T} \leq 50 \mathrm{~K}$. We found that $\mathrm{n}(\mathrm{T})$ measured

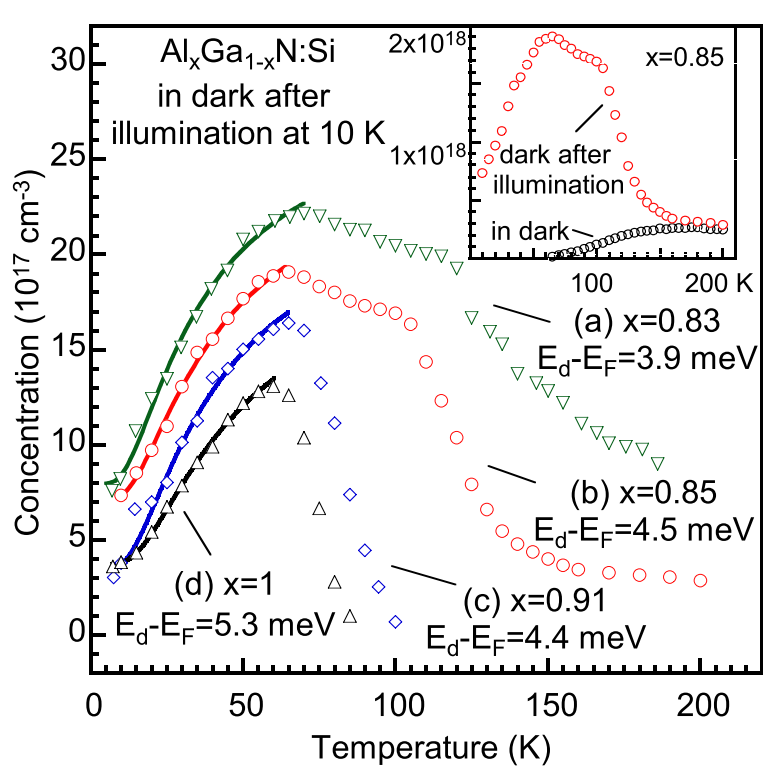

FIG. 4. Temperature dependence of the donor concentration in the $\mathrm{d}^{0}$ state in darkness after illumination at $10 \mathrm{~K}$ in Si-doped $\mathrm{Al}_{\mathrm{x}} \mathrm{Ga}_{1-\mathrm{x}} \mathrm{N}$ with (a) $\mathrm{x} \sim 0.83$, (b) $\mathrm{x} \sim 0.85$ (c) $\mathrm{x} \sim 0.91$ and (d) in Si-doped AlN. The solid curves represent the fits. The inset shows the temperature dependences of the donor concentration in darkness and in darkness after illumination at $10 \mathrm{~K}$ in $\mathrm{Al}_{0.85} \mathrm{Ga}_{0.15} \mathrm{~N}: \mathrm{Si}$ in the same scale for comparison. 
in darkness after illumination increased with increasing temperature and reached its maximum at $\mathrm{T} \sim 60-70 \mathrm{~K}$, which was close to the SIMS value [Si] for all samples, and then rapidly decreased, approaching the values measured in darkness without prior illumination (see the inset of Fig. 4).

The increase of $\mathrm{n}(\mathrm{T})$ in darkness after illumination is typical for a DX center. Thus, the EPR signal measured at low temperatures $(\mathrm{T}<60 \mathrm{~K})$ after illumination should be from another DX configuration whose $\mathrm{DX}^{-}$level lies higher than that of the center detected in darkness at higher temperatures. At $\mathrm{T}<60 \mathrm{~K}$, electrons are confined in this higherlying (or metastable) DX configuration. When temperature exceeds $60 \mathrm{~K}$, thermal energy is enough to help electrons to overcome the barrier between the two DX configurations and to relax to the lower-lying (or stable) DX configuration, leading to the sharp drop of $\mathrm{n}(\mathrm{T})$ (Fig. 4). We label the stable and metastable DX configurations as DX1 and DX2, respectively. For DX2, the temperature dependence of $n(T)$ in the temperature range below $60 \mathrm{~K}$ can be described by Eq. (2) but without the third term in the denominator since the thermal energy is not enough to excite electrons to the excited states. In this case, electrons are confined within the metastable DX2 configuration, and the Fermi level $E_{F}$ is local. For all samples with $x \geq 0.84$, the energy separation $E_{d}-E_{F}$ obtained from the best fit is in the range of $\sim 3.9-5.3 \mathrm{meV}$ (Fig. 4). These values are much smaller than the corresponding values determined in darkness ( $\sim 28 \mathrm{meV}$ or larger), indicating that in this metastable DX2 configuration, the $\mathrm{DX}^{-}$ state is much closer to the $\mathrm{d}^{0}$ state $\left(\mathrm{E}_{\mathrm{d}}-\mathrm{E}_{\mathrm{DX}} \sim 8-11 \mathrm{meV}\right.$ for $\mathrm{X} \sim 0.83-1.0$, respectively). Our observation of two distinguishable DX configurations of the Si donor in $\mathrm{Al}_{\mathrm{x}} \mathrm{Ga}_{1-\mathrm{x}} \mathrm{N}$ for $\mathrm{x} \geq 0.84$ supports the theoretical prediction by Silvestri et al. for Si in AlN. ${ }^{10,11}$

In darkness, transport measurements would probe the stable DX1 center. For AlN, our value $\left|\mathrm{E}_{\mathrm{DX}}\right| \sim 240 \mathrm{meV}$ is close to the activation energy determined from transport measurements for $\mathrm{Si}: \mathrm{E}_{\mathrm{a}} \sim 238-254 \mathrm{meV}^{30}$ and $\mathrm{E}_{\mathrm{a}} \sim 250 \mathrm{meV}$. 5 ,6 The Fermi level found in our experiments for AlN of $\sim 160 \mathrm{meV}$ below the conduction band minimum is also close to the $(+\mid-)$ level of $\mathrm{Si}\left(\sim \mathrm{E}_{\mathrm{C}}-150 \mathrm{meV}\right)$, where the Fermi level is pinned, determined recently from calculations by Gordon et al. $^{22}$ From Eq. (3), the $\left|\mathrm{E}_{\mathrm{DX}}\right|$ value for $\mathrm{Si}$ in $\mathrm{Al}_{\mathrm{x}} \mathrm{Ga}_{1-\mathrm{x}} \mathrm{N}$ with $\mathrm{x}$ in the range of $\sim 0.83-1.0$ can be interpolated, for example $\left|\mathrm{E}_{\mathrm{DX}}\right| \sim 189 \mathrm{meV}$ for $\mathrm{x} \sim 0.94$ which is close to the corresponding $\mathrm{E}_{\mathrm{a}}$ value of $\sim 200 \mathrm{meV}$ determined by Borisov et al. ${ }^{5}$

In summary, our EPR characterization of Si-doped $\mathrm{Al}_{\mathrm{x}} \mathrm{Ga}_{1-\mathrm{x}} \mathrm{N}, 0.79 \leq \mathrm{x} \leq 1.0$, showed that up to $\mathrm{x} \sim 0.83$, the $\mathrm{DX}^{-}$state is still close to the neutral state $\mathrm{E}_{\mathrm{d}}\left(\mathrm{E}_{\mathrm{d}^{-}}\right.$ $\mathrm{E}_{\mathrm{DX}} \sim 9 \mathrm{meV}$ ) and $\mathrm{Si}$ behaves rather similar to a shallow effective-mass donor. For $x \geq 0.84$, two DX centers could be separately observed. For the stable DX1 center, the activation energy $E_{a} \sim\left|E_{D X}\right|$ increases drastically and linearly from $\sim 71 \mathrm{meV}$ in $\mathrm{Al}_{0.83} \mathrm{Ga}_{0.17} \mathrm{~N}$ to $\sim 240 \mathrm{meV}$ in $\mathrm{AlN}$. For the metastable DX2 center, the $\mathrm{E}_{\mathrm{DX}}$ level remains to be close to the neutral charge state $d^{0}\left(\sim 11 \mathrm{meV}\right.$ below $E_{d}$ in AlN). The dependence of the $\mathrm{E}_{\mathrm{DX}}$ level of the stable DX1 center on the Al content explains well the sudden increase of the resistivity in high-Al-content $\mathrm{AlGaN}$ reported by transport measurements.

Support from the Swedish Energy Agency, Swedish Research Council (VR), Linköping Linnaeus Initiative for Novel Functional Materials (VR), the Swedish Government Strategic Research Area Grant in Materials Science (Advanced Functional Materials), and Knut and Alice Wallenberg Foundation is gratefully acknowledged. A.K.G. acknowledges support from the Swedish Governmental Agency for Innovation Systems (VINNOVA).

${ }^{1}$ Y. Taniyasu, M. Kasu, and T. Makimoto, Nature 441, 325 (2006).

${ }^{2}$ Z. Lochner, T.-T. Kao, Y.-S. Liu, X.-H. Li, M. M. Satter, S.-C. Shen, P. D. Yoder, J.-H. Ryou, R. D. Dupuis, Y. Wei, H. Xie, A. Fischer, and F. A. Ponce, Appl. Phys. Lett. 102, 101110 (2013).

${ }^{3}$ N. Norimichi, H. Hirayama, T. Yatabe, and N. Kamata, Phys. Status Solidi C 6, S459 (2009).

${ }^{4}$ M. L. Nakarmi, K. H. Kim, K. Zhu, J. Y. Lin, and H. X. Jiang, Appl. Phys. Lett. 85, 3769 (2004).

${ }^{5}$ B. Borisov, V. Kuryatkov, Y. Kudryavtsev, R. Asomoza, S. Nikishin, D. Y. Song, M. Holtz, and H. Temkin, Appl. Phys. Lett. 87, 132106 (2005).

${ }^{6}$ R. Collazo, S. Mita, J. Xie, A. Rice, J. Tweedie, R. Dalmau, and Z. Sitar, Phys. Status Solidi C 8, 2031 (2011).

${ }^{7}$ F. Mehnke, T. Wernicke, H. Pingel, C. Kuhn, C. Reich, V. Kueller, A. Knauer, M. Lapeyrade, M. Weyers, and M. Kneissl, Appl. Phys. Lett. 103, 212109 (2013).

${ }^{8}$ C. H. Park and D. J. Chadi, Phys. Rev. B 55, 12995 (1997).

${ }^{9}$ P. Bogusławski and J. Bernholc, Phys. Rev. B 56, 9496 (1997).

${ }^{10}$ L. Silvestri, K. Dunn, S. Prawer, and F. Ladouceur, Appl. Phys. Lett. 99, 122109 (2011).

${ }^{11}$ L. Silvestri, K. Dunn, S. Prawer, and F. Ladouceur, Europhys. Lett. 98, 36003 (2012).

${ }^{12}$ D. F. Hevia, C. Stampfl, F. Viñes, and F. Illas, Phys. Rev. B 88, 085202 (2013).

${ }^{13}$ C. Wetzel, T. Suski, J. W. Ager III, E. R. Weber, E. E. Haller, S. Fischer, B. K. Meyer, R. J. Molnar, and P. Perlin, Phys. Rev. Lett. 78, 3923 (1997).

${ }^{14}$ C. Skierbiszewski, T. Suski, M. Leszczynski, M. Shin, M. Skowronski, M. D. Bremser, and R. F. Davis, Appl. Phys. Lett. 74, 3833 (1999).

${ }^{15}$ M. W. Bayerl, M. S. Brandt, T. Graf, O. Ambacher, J. A. Majewski, M. Stutzmann, D. J. As, and K. Lischka, Phys. Rev. B 63, 165204 (2001).

${ }^{16}$ R. Zeisel, M. W. Bayerl, S. T. B. Goennenwein, R. Dimitrov, O. Ambacher, M. S. Brandt, and M. Stutzmann, Phys. Rev. B 61, R16283 (2000).

${ }^{17}$ K. Irmscher, T. Schulz, M. Albrecht, C. Hartmann, J. Wollweber, and R. Fornari, Physica B 401-402, 323 (2007).

${ }^{18}$ S. B. Orlinskii, J. Schmidt, P. G. Baranov, M. Bickermann, B. Epelbaum, and A. Winnacker, Phys. Rev. Lett. 100, 256404 (2008).

${ }^{19}$ V. A. Soltamov, I. V. Ilyin, A. A. Soltamova, E. N. Mokhov, and P. G. Baranov, J. Appl. Phys. 107, 113515 (2010).

${ }^{20} \mathrm{X}$. T. Trinh, D. Nilsson, I. G. Ivanov, E. Janzén, A. KakanakovaGeorgieva, and N. T. Son, Appl. Phys. Lett. 103, 042101 (2013).

${ }^{21}$ N. T. Son, M. Bickermann, and E. Janzén, Appl. Phys. Lett. 98, 092104 (2011); Phys. Status Solidi C 8, 2167 (2011).

${ }^{22}$ L. Gordon, J. L. Lyons, A. Janotti, and C. G. Van De Walle, Phys. Rev. B 89, 085204 (2014).

${ }^{23}$ A. Kakanakova-Georgieva, D. Nilsson, X. T. Trinh, U. Forsberg, N. T. Son, and E. Janzén, Appl. Phys. Lett. 102, 132113 (2013).

${ }^{24}$ A. Kakanakova-Georgieva, D. Nilsson, and E. Janzén, J. Cryst. Growth 338, 52 (2012).

${ }^{25}$ S. R. Lee, A. M. West, A. A. Allerman, K. E. Waldrip, D. M. Follstaedt, P. P. Provencio, D. D. Koleske, and C. R. Abernathy, Appl. Phys. Lett. 86, 241904 (2005).

${ }^{26}$ T. Umeda, J. Isoya, N. Morishita, T. Ohshima, T. Kamiya, A. Gali, P. Deák, N. T. Son, and E. Janzén, Phys. Rev. B 70, 235212 (2004).

${ }^{27}$ D. Adler and E. J. Yoffa, Phys. Rev. Lett 36, 1197 (1976).

${ }^{28}$ N. W. Ashcroft and N. D. Mermin, Solid State Physics (Thomson Learning, London, 1976), p. 581.

${ }^{29}$ D. C. Look, Phys. Rev. B 24, 5852 (1981).

${ }^{30}$ Y. Taniyasu, M. Kasu, and T. Makimoto, Appl. Phys. Lett. 85, 4672 (2004). 